\title{
Misusing the City Statute in São Paulo: the Nova Luz urban renewal project
}

\author{
P. Rodrigues Samora \\ Laboratory of Housing and Human Settlements, \\ Faculty of Architecture and Planning, São Paulo University, Brazil
}

\begin{abstract}
Brazil is known for its accomplishments in the field of urban legislation, particularly regarding the 2001 City Statute. São Paulo was a pioneer city in this regard, and the first to integrate instruments from this groundbreaking law into its 2002 Master Plan. As a result, some areas of the city were designated as Zonas Especiais de Interesse Social (ZEIS, or Special Zones of Social Interest), which include some of the city's poorest areas. These vary from informal settlements to neglected but transportation-rich neighborhoods in central districts. Considering social housing as a priority and the social function of the urban land, the ZEIS are in tune with the ideal of a sustainable city. However, ten years after the implementation of the ZEIS's, the access of the poor population to well-located areas in São Paulo is still deficient. While land and tenure regularization of peripheral, informal settlements designated as ZEIS is now easier than before, the central ZEIS are not being used by the local government to expand social housing in well-located areas. This paper discusses the case of the "Nova Luz", an urban renewal project that provides an example of the misuse of the central ZEIS - and to a certain extent, of the City Statute as well. In this project, a ZEIS is considered as a "reservoir" for the poor, a small island where a few will be allowed to stay while many will be evicted and displaced. Even worse, the ZEIS has been used to mitigate the impacts of a massive public-private redevelopment project and thereby legitimate mass evictions, an issue that has become increasingly critical in the Brazilian economic boom and redevelopment spurred by the 2014 World Cup and the 2016 Olympics.

Keywords: urban renewal project, compact city, gentrification, inclusive city, affordable housing, Brazil.
\end{abstract}




\section{The City Statute and the unequal urban environment}

\subsection{The informal and unequal urban environment}

The City Statute (CS) is a Brazilian Federal Law that regulates the constitutional chapter related to urban policies. Enacted in 2001 after 13 years of intense debate, this legal framework provides the cities with legal devices to overcome urban and environmental liabilities arising from the rapid urbanization process experienced in the last century. In fact, Brazil moved from a predominantly rural condition in 1940 , when only $31 \%$ of its population lived in cities, to become an urban giant. At the time of the adoption of the Statute, the country had a population of almost 170 million inhabitants, out of which $81.2 \%$ occupied urban areas.

This fast growth was not followed by an appropriate distribution of income and wealth that was then generated in the country and Brazil ended up in the last century as one of the most unequal countries in the world. As a result, its cities are the materialization of spatial inequality, characterized by social exclusion, violence and environmental problems resulting from uncontrolled growth. A striking example of the Brazilian social inequality and its effects on urban areas is the access to housing. Historically, many urban workers were incorporated into the Brazilian labor market (both formal and informal) with low wages. Their income was insufficient to ensure access to formal housing, either through the rental market or through housing mortgages. In the same period, the welfare program initially implemented in the country in the mid-30s did not include social housing for low-income families in its benefits. Without options in the market or from public policies, a large number of families were forced to build their own houses wherever they could afford the price of the land, mostly pirate settlements or slums located in the fringes of the city. Many informal settlements are in areas unsuitable to urban uses, such as water springs, forests, wetlands and other environmentally protected areas. As the borders of the main Brazilian cities have expanded, the price of the land in well-located areas rises at a constant pace and is unaffordable to most poor Brazilian families.

The peripheral occupation was often promoted by housing policies that have built - since the 70s - huge developments with hundreds of thousands of units disconnected from the main urban area. Many of them were delivered to the residents without basic infrastructure, such as sidewalks, transportation, sanitation, and urban facilities like daycares and hospitals, worsening the quality of life of local residents. This general trend has been aggravated by many economic crises since the 80s, when unemployed families left their homes in consolidated areas to occupy slums and other informal settlements with disastrous effects to the cities. Entire poorly developed neighborhoods were built over fragile areas, aside to the urban legislation, where land was cheaper due the legal restrictions, which often became high-risk areas.

In the central and consolidated neighborhoods, poor families can only find housing in tenements or slums that have not yet been removed by public city embellishment policies. In these places, the conditions of life can be even worse 
than in poor suburbs. As they are well-located, near to business districts, this type of housing tends to be much disputed and every square meter is densely used, leading to high levels of crowding and unhealthiness.

\subsection{The urban reform movement and the City Statute}

With the advent of democracy after the dictatorship (between 1964 and 1984), several groups began to mobilize and demand housing and better urban conditions. This process, known as the Urban Reform Movement, had an important victory in the Constitution of 1988, when a chapter was included to the urban policy to be regulated by a specific law. Only in July 2001, thirteen years after the constitution's enactment, a favorable political environment was obtained to pass this law, which was then denominated the City Statute (CS).

The CS has four main dimensions: a conceptual one, providing elements for the interpretation of the constitutional principle of the social functions of urban property and of the city; the regulation of new instruments for the construction of a different urban order by the municipalities; the indication of processes for the democratic management of cities; and the identification of legal instruments for the comprehensive regularization of informal settlements in private and public urban areas [1].

An important element of the CS is the strengthening of the constitutional principle of the social function of cities and urban properties. According to this principle, another constitutional right, the ownership, began to be regulated from the perspective of its social function. This means that the right to urban property is guaranteed, provided that it fulfills its social function, to be defined by the municipal legislation. The municipal government was given the power to, by means of laws and several urban planning and management instruments, determine the scope of this (possible) balance between the individual and collective interests over the use of this non-renewable and essential resource to the sustainable development of cities, that is, urban land.

The social participation in all instances of the planning process is an innovation of the CS. The CS also provided municipalities with legal instruments to promote land tenure, thereby assuring housing rights at informal settlements, with the support of a legal framework that is common to the whole country, with positive social and environmental impacts.

After the enactment of the CS, the role of municipalities in relation to the control of its urban order is recognized. Thus, cities have instruments to be regulated and used according every single context, defined in their master plans. These, in turn, assist municipalities to control land speculation, one of the major contributor to the increasing urban land prices and consequent expulsion from the poorest of the best and suitable locations. Every city whose population is higher than twenty thousand inhabitants or cities located in historic or environmental protected sites had to develop its Strategic Master Plan according to Statute Principles. São Paulo was the first Brazilian capital to formulate and approve its Master Plan, in 2002. 


\section{Urban sustainability in the Sao Paulo's strategic master plan}

\subsection{The urban context of São Paulo}

The economic capital of the country and Mercosur's regional center is, as many affirm, a divided city [2]. The vast majority of its population (57\%, according to census data from 2000) lives in the suburbs and an average of one third of the housing units are located in substandard settlements. On the other hand, the wealthy elite demonstrates better health and education indexes and live in good neighborhoods that have experienced a decreased in their populations in the last decades.

Among the types of informal settlements in the city, slums and illegal subdivisions are the most frequent. While slums or favelas are roughly characterized by spontaneous and unplanned occupation, illegal subdivisions usually have a better-organized urban layout, with lots and streets designed according to a previous plan. They occupy urban interstices, riverbanks and slopes, as these areas are not in the interest of the real estate market because of their urban and environmental restrictions. Slums have higher density rates, showing also others problems that result from building conditions and human congestion. Many are located in areas at risk of flooding or landslides, for which a solution would require the removal of shacks and houses at risk, displacing families to other locations. This requires available urban land and infrastructure elsewhere.

Since the 70s, central districts have lost inhabitants while peripheral areas are overcrowding. While the availability of land suitable for housing in peripheral areas gets scarcer, central districts lose population and many of its buildings are emptied. Family income in central neighborhoods grew in that period, while the suburbs experienced the growth of a higher number of low-income households. While the peripheral growth occurred in poor neighborhoods, central districts benefit the most from public funds to improve the best urban locations, which reinforces the urban gentrification process in those areas. As a result, the average population density in the city of São Paulo in 2008 was 69 inhabitants per hectare, while in the slums this number was seven times higher.

A research from 2007 revealed that the vacancy rate was over 400,000 housing units throughout the city, which stands for $11.8 \%$ of the total urban domiciles. Back then, central districts had 41,085 vacant homes, $18.5 \%$ of the total 221,614 domiciles in the area [3]. These data indicate that much of the existing housing stock is empty and could be used to mitigate the housing shortage changing the current dynamics of urban sprawl and overcrowded informal settlements.

In view of this picture, the "sustainable city" will be accomplished through the control of the use of the urban land and by overcoming some challenges. The former, related to the uncontrolled population growth over the most environmentally fragile areas can be reversed by increasing adequate housing stocks and upgrading informal settlements. While slum upgrading improves the 
environmental conditions and housing at informal settlements, this action requires new housing units outside these neighborhoods to accommodate part of the population that needs to be removed due risks or other unsafe urban conditions. The supply of well-located social housing helps to mitigate the propagation of slums and the population growth in the suburbs, with positive effects. It also influences the demand for mass transportation and urban services at the edges of the city. However, the production of social housing depends on affordable land prices that allow their acquisition either by the government, residents' associations, or private entrepreneurs. This leads to another central problem in the urban development of the city, which involves the speculative retention of land in consolidated areas. These complex dynamics have influenced the development of São Paulo's master plan, approved in 2002.

\subsection{Democratic planning towards urban sustainability}

The São Paulo's Strategic Master Plan has principles addressing justice and social inclusion, the reduction of social and regional inequalities, the individual right to the city, the right to decent housing, and the respect for the social functions of the city and property. It expresses the city's understanding of urban sustainability and democratic planning, to be achieved through justice and social inclusion, empowering all citizens to access the urban benefits produced collectively. These principles lead to objectives and actions and include sectorial policies (housing, transportation, sanitation, and so on). In order to approach regional differences in a giant and heterogeneous city as São Paulo, the municipal plan established the obligation of every district in the city to produce local plans, which must be developed through consultation and participation.

According to Budds and Teixeira [4], São Paulo's master plan revised completely the urban development strategy. The new legislation was designed so as to prevent speculation in the property market (and thereby promote the development of areas that already have infrastructure), stimulate the production of low-income housing, prioritize interventions in low-income settlements, and legalize land tenure by low-income residents.

\subsection{The ZEIS concepts, goals and performance}

The new instruments in the Master Plan include the Zonas Especiais de Interesse Social (ZEIS - Special Zones of Social Interest), a zoning categorization with the following characteristics: 1) legalize land tenures that fail to comply with conventional planning standards, as long as the settlement has basic infrastructure and adequate living conditions; (2) enforce the compulsory development of undeveloped or underused properties and expropriate them when the owner fails to comply; and (3) require that entrepreneurs produce a given proportion of social housing units in all (re)developments [4]. Initially, 964 ZEIS were delimited in the city by the regional master plans.

Any development in these territories should follow the parameters established by a previous ZEIS's urban design plan, considering the total zoning perimeter, which establishes specific building and urban parameters for a given area. A 
ZEIS's managing board should be established in order to develop and to approve the plan using a participative planning approach. The managing board must be headed by the Department of Housing and Urban Development (SEHAB) and include landowners and residents representatives. For the first time in the city, collaborative planning was provided for in the urban legislation.

Four ZEIS categories were established, each one with different purposes. While ZEIS categories 1 and 4 address the regularization of informal settlements, the other two categories aim at the development of underused land for housing purposes. ZEIS 2 aims at producing housing and infrastructure in suburban neighborhoods, establishing that developments in those areas must have at least $60 \%$ of housing use. In central neighborhoods, where tenements, squats and slums are located and equipped with abundant infrastructure to withstand a large population density, ZEIS's 3 were set out in perimeters containing underused plots or buildings. In these ZEIS's, $80 \%$ of the total built area in any development located in plots larger than 500 square meters must be used for social housing (HIS) or popular market housing (HMP). According to previous definition, a HIS is dedicated to families with a monthly income of up to 6 minimum wages and a HMP is dedicated to families with a monthly income of up to 16 minimum wages. The Brazilian Minimum Wage is determined by the law and is currently set at R\$ 622.00 , or US\$ 360.68 . In order to develop a ZEIS 3 , these places could be built more densely than other areas. With this additional built area, the land price is shared by more housing units, thus creating conditions to increase well-located affordable housing.

However, in spite of the fact that the federal government has increased the housing funds since 2005, ZEIS 3 has not had the same performance as ZEIS 1 when it comes to new redevelopments. The municipal government of São Paulo has advertised its slum upgrading program all over the world, without a single housing project in ZEIS 3 as part of the show. Even though, only one ZEIS 3 has been developed since the approval of the district's master plan. Other housing buildings have been built in ZEIS areas by the State of Sao Paulo's Housing Company, a state-owned company that had the property rights over those areas before the establishment of the ZEIS. These are punctual developments and were approved by the municipality without a previous ZEIS's plan. In other words, the proposal designed by the Strategic Master Plan - supported by the City Statute to promote a model of a compact and inclusive city through the recovery of neglected areas for housing needs has not yet taken off.

The reasons for such an imbalance are: the consolidation of slum upgrading policies in opposition to previous eviction practices; favorable conditions to upgrade informal settlements when they do not require additional land to shelter removed families; increased housing funds, allowing families that were previously excluded from the market to access credit, which impacts the demand for lands and their prices. Yet, and above all, projects in ZEIS 3 have not been developed due to the lack of political will. Since 2005, Sao Paulo has a conservative government more connected to landowners and real estate market, which is trying to suppress some ZEIS by reviewing the Master Plan. As a 
response, the housing movement is promoting squat of empty buildings in order to sensitize the government to produce housing in the inner city, without success.

The municipality has developed many urban projects in the central districts without consideration to their effects on low-income groups, which tend to be shooed away from the inner city. These projects aim at the needs of higher income groups and are in line with the expectations of the real estate market. The case of the "Nova Luz" [New Luz] project, where ZEIS 3-C015 and ZEIS 3$\mathrm{C} 016$ are nestled, is a meaningful example of that.

\section{3 "Nova Luz" and its sustainable city concept}

\subsection{Context of the "Nova Luz" project}

As many other traditional, high-income neighborhoods, Luz and Santa Ifigênia have lost population along the last century and have then been occupied by popular businesses and housing. The exodus of the local elite to other central regions has also driven the public investments, thereby impacting the urban conditions in those areas. Attracted by falling rental prices and good locations, poor workers began to occupy old buildings. Neglected by the municipality, a process of decay took place in those areas. Many uses, including drug dealing and prostitution, took over entire regions. However, streets like Santa Ifigênia have developed specialized formal businesses, such as electronics and car parts, attracting thousands of customers from Brazil and abroad every day. These two neighborhoods are intensely used by lower and medium income groups and, in spite of its problems, the current local occupation density is four times higher than the city's average. According to the Census of 2010, the República district, which has jurisdiction over "Nova Luz", holds an average population density of $27,833.41$ inhabitants per square kilometer, while the average population density in the whole city is $7,387.69$.

In the last decades, the State government has invested in the area in order to recover it and turn it into a cultural spot. The São Paulo Concert Hall and some museums were opened, but these initiatives have not been able to change the overall status of abandonment and do not address the users' daily urban needs, such as daycares and a renovated infrastructure. In 2011, the multimodal Luz train station was connected to a new subway line, becoming the most important urban and regional transportation hub. From it, in fifteen minutes, one can reach Faria Lima station, located in the city's wealthy business district. This fact has an impact on real estate prices in the area, shooting away families that cannot afford the increasing rental prices.

\subsection{Compact city and urban concession model}

To take advantage of this region, the municipality conceived the "Nova Luz" project. In a public-private partnership, the city intends to "renovate" 45 blocks in the neighborhoods of Luz and Santa Ifigênia in the name of "compact city" to alleviate sprawl. To do so, the government is using "urban concession" — a legal 
instrument that allows the municipality to tender projects to private companies, provided that they serve a public purpose - to evict residents, demolish old buildings and build new ones. Only a single entity (or a pool of companies) will implement the entire Nova Luz project, worth 750 million Brazilian Reais (450 million US Dollars) in five phases. One third of the area will be cleared up to make room for new apartment and office buildings, particularly for medium and high-income groups. Inspired by Barcelona's Ramblas, the project seeks to create boulevards, movie theaters, shopping malls, restaurants, parking places and other facilities [5].

The municipal councillors approved the urban concession model in 2009. During the debates, the government argued that the model was a mechanism through which urban improvements (including infrastructure) could be made without the need for public funding. The scheme was seen as a controversial one, as any landowner or user could then be expropriated for a price lower than current market prices, without any participation in the supposed urban improvement. To attract investors, the government will grant an exemption of up to $60 \%$ in taxes for these developments. However, the economic feasibility study pointed out that at least 355 million Brazilian Reais should come from public resources. The total amount of revenues expected after the conclusion of the five phases would be 5 billion Brazilian Reais.

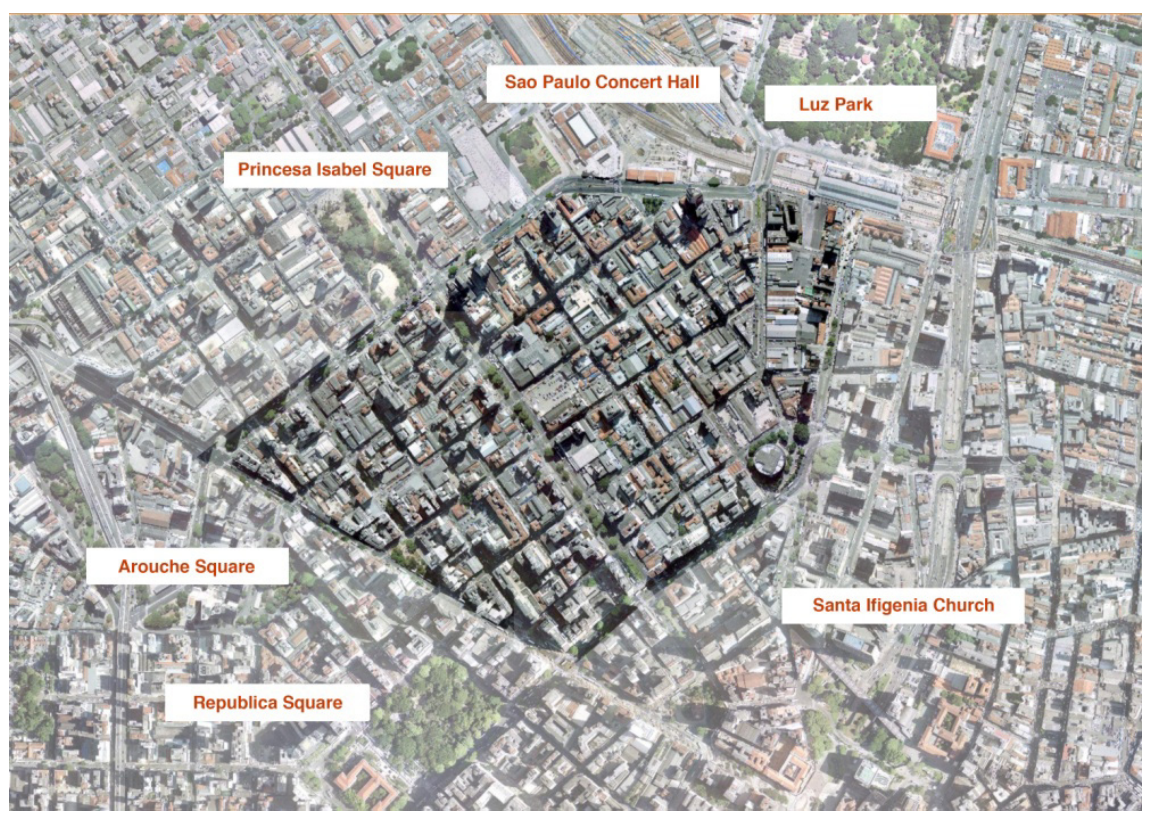

Figure 1: "Nova Luz" blocks [5].

The project seeks to increase density in the region by developing underused areas where low land prices will later generate great profit. Thus, wherever zoning allows, old housing and business buildings will be replaced with new 
buildings that allow for more profitable uses. According to the project data, one million square meters will be added to the current built environment, an increase of $94 \%$.

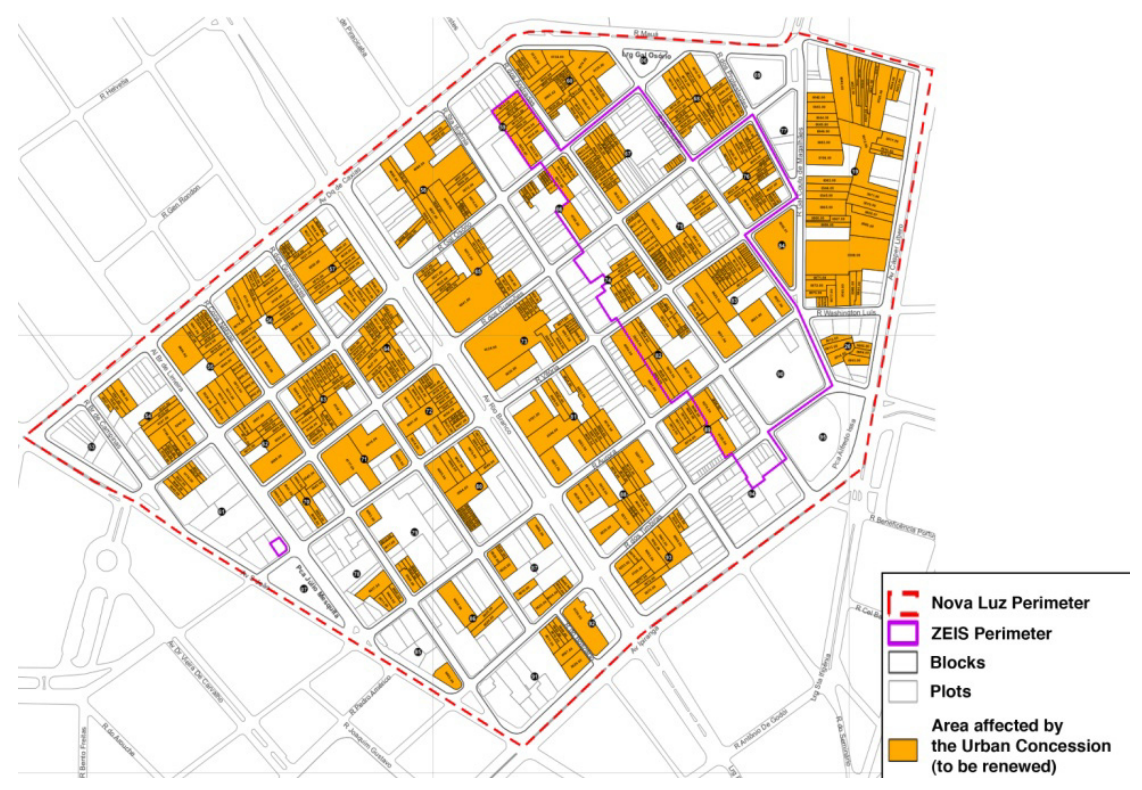

Figure 2: $\quad$ ZEIS perimeter and area affected by the Urban Concession [5].

\subsection{For whom is the sustainable city?}

Residents and local users claim that the project does not address their current needs and, instead, is intend to reach out to a different public and attract it with said new developments. One example is the proposed housing project that implements approximately 5,000 units within the perimeter. While $62 \%$ of the current residents live and work in the area, $47 \%$ live in rented units. None of the new houses will be dedicated to social rental policies. Therefore, only those who can afford a mortgage will be entitled to purchase a new flat. It means that the "Nova Luz" project did not consider the local, current population in its concept.

Many current residents are part of the housing movement. Since the 90s, this group has squatted 44 old, empty buildings in the inner city, bringing more than 10,000 families to the area. Their actions have been more successful than the local housing policies, which have produced only 2.833 housing units in the last ten years. This group was ignored by the "Nova Luz" project, which plans to remove the squat at the Mauá Street, a building that is now home to 253 families.

According to the Registry of Occupants made by the municipal government, $44.39 \%$ of the families earn a monthly income of up to 3 minimum wages, and $36.99 \%$ total a monthly income between 3 and 6 minimum wages. This means that $81.38 \%$ of the occupants are entitled to benefit from public subsidies for social housing (HIS). Those entitled to popular market housing (HMP) total 
$15.14 \%$ of the households, with 6 to 12 minimum wages per month, followed by $1.93 \%$ of families that make 12 to 16 minimum wages as per month. The "Nova Luz" project will only develop the HIS zone inside the ZEIS perimeter. The economic feasibility study states that housing outside the ZEIS areas would only be accessible to families that make more than 7 minimum wages per month.

Another group not addressed by the project is comprised of current homeless people, and many of them are drug addicts. The project's survey indicates that 922 people, representing $7 \%$ of the overall homeless population in the inner city, can be found in this condition. These citizens do not have access to any housing credit due to their social problems, and are therefore ignored by the project.

As for work and income-generating activities, there is a disparity between the will to create new businesses and protective measures to the existing commercial activities. The project aims at increasing the employment rate in the region, but it doesn't even mention a plan to mitigate the impacts (especially due to increased rental prices) over the 2,278 current businesses and 16,806 jobs.

One more concern involves the elimination of the intangible heritage. The project did not take into account the region's cultural wealth, where groups of relevant musical expression regularly gather in bars and musical instrument stores, producing entertainment of high quality for free. These practices were ignored and areas to accommodate them have not been provided.

Almost all the public area within the "Nova Luz" project was planned to host private activities. Except for a new square on Conselheiro Nebias Street, the public urban space will be comprised of sidewalks, "rain gardens" and bicycle lanes, which are elements of a sustainable city, according to the project. Libraries, playgrounds and sports facilities, which gather different social groups and bring life to any neighborhood, were not planned.

As discussed so far, the concepts of a sustainable city and social interest was poorly developed in the "Nova Luz" project. For the sake of sustainable city, most current users will be evicted with the use of public funding, meaning that São Paulo is losing an opportunity to promote inclusive and democratic urban solutions.

\subsection{Misusing ZEIS in the "Nova Luz" project}

When the press started to publish information about the project, an association of residents named AMOALUZ [Residents and Friends of the Neighborhoods of Luz and Santa Ifigênia]was created to debate with the government. AMOALUZ denounced that, even though the project planned developments in ZEIS 3 areas, a ZEIS's Managing Board had not been established.

The ZEIS's Board was established after the project's first public hearing and discussed the urban proposals. However, the Board's action area includes the ZEIS only, which stand for approximately $25 \%$ of the total perimeter. The Board has developed guidelines for the ZEIS area that should impact the current proposal.

According to the project, the ZEIS will be used to receive part of the population evicted from other areas within "Nova Luz". As previously presented, old buildings and squats will be swept way to give room to other (profitable) 
uses, while the ZEIS — legally restricted to social housing — will help mitigate the impact of such evictions. This scheme doesn't guarantee that traditional lowincome residents can remain. Many will not be able to afford or even qualify for the new housing program in the ZEIS. Moreover, many residents that depend on affordable rental prices have already been displaced. Thus, the ZEIS concept is being misused, as it fails to expand the housing stock, as previously provided for in the law, and, instead, supports a massive urban project. The total number of HIS will be developed only inside the ZEIS perimeter.

\section{Conclusions: central ZEIS and the hope of sustainable city}

So far we have seen how the ZEIS' instruments, and consequently the very principles of the City Statute, have been distorted in the "Nova Luz" project. In lieu of having ZEIS's expand the housing stock in the central region of São Paulo, in "Nova Luz" it will be used to receive residents removed by the urban project, but only those who can afford the mortgage proposed. The dialogue between the municipality and the citizens was based on two public hearings in which the project was briefly explained, while the participants - many of which were taking part of such proposals for the first time - could barely understand the urban impact to later formulate questions about it.

The ZEIS Managing Board's role has been critical in this process, as it forces the municipal government to review central points of that proposal. Among the many issues raised and currently under analysis by the municipality, the following outstand: creation of a census-registration of all residents in order to better define the housing project proposed; maintenance of the squatted building on Mauá Street, currently out of the ZEIS area and to be demolished in the preliminary project; inclusion of housing developments for social rent by residents that cannot afford a mortgage in the region; permanence of some meeting points and collective practices, such as Bar Léo, a famous bar that attracts consumers from all over the city; assistance to drug users included in the services to be implemented by the project. Should these proposals be accepted, the "Nova Luz" project may then become an example of how social participation acts as a determinant factor to the development of more appropriate interventions that consider the holistic sustainability concept of the "3 E's" principle: environment, economics, equity. When unbalanced, as seen in the initial "Nova Luz" project, the results can be opposite to the expectations. If accepted, they would represent the confirmation of the ZEIS as a central instrument to implement a culture of participative planning in public policies, opposite to the technocrat practices that have been taking place.

The "Left Hand Rotation" collective, in a partnership with the "Museo de Los Desplazados", from Madrid, and AMOALUZ, has recently elaborated a workshop with residents to discuss the project and clarify its impacts on the lives of users [6]. The group traveled through the neighborhood streets and used wheatpaste posters to literally "tag" the buildings to be demolished. These wheatpaste posters had five different colors to represent each phase of the project and informed the remaining life time of each building. This demonstrated the 
changes planned for the neighborhood in a more concrete way and beyond technical speeches, which often fail to be fully understood by the population, preventing the effective participation of local residents. As a result, many residents and users of these neighborhoods that were not aware of the intervention began to understand it and take more active participation in the discussions on the future of the region with the association of residents. This process has also assisted the ZEIS Managing Board in its revision proposal regarding planned demolitions. As the board is the only entity with a communication channel with the municipal government, the memory of the neighborhood is expected to be respected through the board's suggestions. However, the municipal government has made no commitment to accept board's proposals other than those directly related to the ZEIS areas.

A question that remains unanswered is related to how a project of such magnitude, such a huge social impact, can be justified as a public utility project and then profit from the instrument of urban concession. It is imperative that the project be adjusted from a social perspective, where the new - "Nova" and the old can coexist. Otherwise, it may represent the opposite of what it defends when it advocates the construction of a more sustainable city, where economic interests prevail over all the others. As it is today, the "Nova Luz" project is not at all different from the traditional urban practices in the city, which prioritized real estate speculation areas and pushed the poor population to peripheral areas, with dramatic consequences.

\section{Acknowledgements}

The author gratefully acknowledges the financial support of FAPESP Fundação de Amparo à Pesquisa do Estado de São Paulo (Grant Proc. 2010/20664-2).

\section{References}

[1] Instituto Polis \& UN Habitat. The Statute of the City New Tool for assuring the right to the city in Brazil. Online. www.polis.org.br/obras/ arquivo 163.pdf

[2] UN Habitat. Sao Paulo, a tale of two cities. Online. www.unhabitat.org /pmss/getElectronicVersion.aspx?nr=2924\&alt=1

[3] Silva, H.M.B \& Sigolo, L.M. Oportunidades e limites para a produção de habitação social. 2007. Online. www.usp.br/fau/depprojeto/labhab/ biblioteca/textos/silva_oportlimites_prodhabsocial.pdf

[4] Budds, J. \& Teixeira, P. Ensuring the right to the city: pro-poor housing, urban development and tenure legalization in São Paulo, Brazil. Environment and Urbanization, vol.17, pp. 89-114, 2005.

[5] Nova Luz, www.novaluzsp.com.br/proj_plano.asp?item=projeto.

[6] Museo de los Desplazados \& Left Hand Rotation, http://lefthandrotation.com/museodesplazados/ficha_luz.htm 